\title{
RESENHA
}

\section{Um Congresso pela conciliação}

\author{
Cláudio Beserra de Vasconcelos
}

REGO, Antônio Carlos Pojo do. O Congresso Brasileiro e o Regime Militar (1964-1985). Rio de Janeiro: Editora FGV, 2008, 316 páginas.

O cientista político Antonio Carlos Pojo do Rego (1948-2007) dedicou grande parte de seu trabalho à análise do Congresso Brasileiro. Em particular, ocupou-se do período que envolve a ditadura civilmilitar implantada no Brasil em 1964. Escreveu artigos, livros e capítulos de livros sobre o tema, e $O$ Congresso Brasileiro e o Regime Militar (1964-1985) corresponde a uma versão atualizada de sua tese de doutorado em Ciência Política pela State University of New York (SUNY-Albany), defendida em 1997.

Membro da Brazilian Studies Association (BRASA), grupo internacional e interdisciplinar de analistas dedicados à promoção de estudos sobre o Brasil ao redor do mundo e, principalmente, nos Estados Unidos, Pojo, como era conhecido, nunca abandonou a Ciência Política, mas, durante a maior parte da sua vida profissional (de meados da década de 1970 a meados dos anos 2000) exerceu a função de assessor parlamentar no Congresso Brasileiro, em ministérios e outros órgãos públicos. Esta experiência permitiu que ele se tornasse um observador privilegiado da vida política brasileira, em especial, daquele que se tornou o tema mais frequente de suas análises.

Em O Congresso Brasileiro e o Regime Militar, Pojo mantém um diálogo com o cientista político argentino Guillermo O'Donnell. Por um lado, concorda e adota a classificação do regime instaurado no Brasil como burocrático-autoritário. Por outro, critica O'Donnell, por lamentar ter a transição brasileira ocorrido sem maiores rupturas com o passado. Defensor da ideia de que a conciliação que marcou a passagem do autoritarismo para a democracia foi melhor do que uma possível ruptura, Pojo sustenta que Congresso foi o maior responsável pela adoção deste padrão. Por isso, refinando a classificação de O'Donnell, denomina o caso brasileiro de um "autoritarismo consultivo" que é, aliás, o título original da tese. ${ }^{1} \mathrm{Ou}$ seja, um tipo de regime onde o Executivo exerceu o controle sobre a sociedade, mas levando em consideração os insumos apresentados por atores políticos, no caso, os parlamentares.

Pojo procura demonstrar que ao longo de todo o período ditatorial o Congresso exerceu a função de legitimador do regime e de representação dos eleitores, mas, em um primeiro momento, seu papel foi mais consultivo, tendo funcionado como tábua de ressonância para as propostas do governo. Posteriormente, sua atuação foi mais efetiva, tornando-se um conciliador entre as demandas da sociedade e o Executivo. Por fim, pela sua oposição, agiu como impulsionador na transição política para o regime civil. Mas, mesmo nesta última fase, marcada pela contestação crescente, também trabalhou como um fórum para viabilização de ações de natureza conciliatória entre diferentes frações da elite nacional, no caso, o governo e a oposição moderada. Para Pojo, este posicionamento do Congresso, ocorrido dentro de um ambiente institucional de legalidade, contribuiu para que se evitasse uma possível ruptura.

Apesar de afirmar procurar respostas que expliquem por que o Legislativo brasileiro permaneceu aberto e desempenhando um papel institucional importante no sistema político durante o regime militar, o que Pojo tenta realmente é, a partir de um estudo de caso, comprovar a hipótese de que a política brasileira tem sido centrada no exercício da conciliação e de quanto esta opção foi benéfica para o país. Como suporte, recorre à análise do historiador José Honório Rodrigues, ${ }^{2}$ que 
identifica esta tendência histórica na nossa sociedade e a apresenta como resultado de uma postura pragmática dos principais atores políticos brasileiros diante de uma constante preocupação com a possibilidade de uma rebelião social. Este temor teria reforçado nas frações da elite a necessidade de solucionar os seus conflitos através de uma forma não violenta e explicaria o fato dela sempre ter procurado controlar e dirigir os processos de mudança de acordo com seus interesses. Para Pojo, esta questão seria a chave para a explicação da manutenção do Legislativo durante o regime militar como o local ideal para a conciliação.

Mais do que se opor às análises que frisam uma suposta falta de funçóes e de importância do Congresso brasileiro ao longo dos anos ditatoriais, Pojo parece tomar o partido do seu objeto e da prática conciliatória. Nesse sentido, as ações do Legislativo são, por vezes, supervalorizadas e toda opção em sentido contrário à conciliação tende a ser apresentada como equivocada. O que compromete a análise, porém, não é o fato de determinada ação poder ser julgada como um erro, e sim a parcialidade dos elementos utilizados para comprovar tal hipótese. Isto é perceptível no exame das tentativas da oposição dita "radical" de destruir a fachada democrática e de demonstrar a falta de legitimidade do regime.

No caso do discurso do deputado Márcio Moreira Alves, usado como pretexto para a decretação do Ato Institucional no 5 (13/12/1968), por exemplo, Pojo discorda dos estudos que consideram o pronunciamento como uma ação sem maiores pretensóes que foi manipulada pelos militares da "linha-dura" no intuito de endurecerem o regime. Para tanto, usa o depoimento de Jarbas Passarinho, ministro do Trabalho e da Previdência Social na época, e um livro de autoria do próprio deputado $^{3}$ para afirmar a intenção dos "radicais" de forçar o governo a agir contra o Congresso. Ao mesmo tempo, desconsidera as alegações de Alves, dadas em um depoimento concedido ao autor no ano de 1997, de que o governo estaria forçando uma derrota no caso do pedido de licença para processá-lo.

A questão é que Pojo não problematiza o uso das fontes, em especial as orais. Ele assume como verdadeiras as opiniōes de atores profundamente ligados a uma determinada posição político-ideológi- ca (em especial os de Passarinho, figura onipresente ao longo de quase todo o livro e cujos pensamentos são constantemente usados para corroborar as teses do autor), não se questiona quanto ao contexto em que tais relatos foram produzidos e nem quanto ao papel e aos interesses de quem os proferiu. Isto é explícito quando toma como correta a afirmativa do ex-ministro de que o AI-5 foi, antes de tudo, uma punição aplicada ao Congresso (p. 93).

Embora reconheça a importância do papel dos "radicais" na defesa das liberdades políticas e dos direitos humanos, Pojo considera que sempre que prevaleceu tal escolha, a oposição saiu enfraquecida. Além do caso que resultou na decretação do AI-5, isto teria ocorrido em 1970, quando os oposicionistas adotaram a proposta de defesa do voto nulo, o que contribuiu para a vitória do governo, a redução da presença da oposição legal no Legislativo e, em consequência, a diminuição da possibilidade de uma ação política institucional. Como sustenta a tese de que a opção pela conciliação mostrou-se mais adequada ao longo do tempo, crê que somente em 1974, época em que predominou a estratégia moderada de atuação dentro do sistema, é que a oposição ganhou terreno e a liberalização se tornou menos difícil. Pojo parece desconsiderar o momento em que cada uma das estratégias foi traçada. Se a dos moderados mostrou-se a mais correta, não há como esquecer que a sua adoção se deu já no início da fase de descompressão do regime. Nada garante que, se tomadas em 1968 ou 1970, teriam o mesmo sucesso.

Em um segundo momento de O Congresso Brasileiro e o Regime Militar, Pojo se volta para o exame dos novos papéis assumidos pelos parlamentares no processo de formulação de políticas públicas.

A primeira indicação a este respeito teria ocorrido no início dos anos 1970, quando o Legislativo funcionou como canal de informação entre a periferia do país e o centro administrativo. Através dele, as elites políticas e econômicas regionais teriam agido como um lobby organizado, que permitiu ao governo tomar conhecimento de demandas de políticas públicas apresentadas por diferentes grupos sociais e econômicos de diversas regiōes do país. Como exemplo, cita a criação, pela liderança da Aliança Renovadora Nacional (Arena), da Comissão Coordenadora de Estudos do Nordeste 
(Cocene), em 1971. Depois, já no final daquela década e início da seguinte, o Congresso teria passado a trabalhar como foro de debates para discussão de visões antagônicas sobre a formulação e a implementação destas políticas. Prova desta atuação teria acontecido durante a discussão a respeito da soberania sobre a região onde foi desenvolvido o Projeto Jari. Neste caso, o Legislativo, através do sistema de comissões, teria permitido a difusão de visões da oposição e, por fim, influenciado para que se chegasse à solução final de aquisição da região por uma holding formada por empresas brasileiras. Neste mesmo período e como exemplo da participação ainda mais efetiva do Congresso na formulação de políticas públicas, Pojo menciona o processo de elaboração de uma legislação referente ao setor de informática. Neste caso, os parlamentares apresentaram projetos de lei, requisitaram informações, cujo objetivo seria o de chamar a atenção do governo e da sociedade para determinados aspectos da questão, e votaram e emendaram o projeto submetido pelo governo, de modo a torná-lo menos autoritário. Em paralelo, como havia uma cisão no interior do Executivo entre os defensores da abertura dos mercados e a Secretaria Especial de Informática (SEI), o Legislativo funcionou no sentido de solucionar este conflito.

Em todos estes casos, tenho a impressão de que há uma valorização e uma positivação excessiva do papel do Congresso. No que se refere à criação da Cocene, embora Pojo observe que a ação poderia ser apenas resultado da preocupação dos parlamentares com a imagem que era passada para a opinião pública, ao final ele tende a enfatizar não só papel consultivo do Congresso, mas também a suposição da preocupação dos congressistas com os problemas da região. Porém, a observação de Pojo quanto ao interesse dos parlamentares em resgatar suas imagens serve para que se questione se realmente os parlamentares envolvidos na Cocene estavam mais preocupados com os problemas da região ou em defender seu futuro político.

Já com relação ao Projeto Jari e à formulação de uma política para o setor de informática, Pojo dá relevo à influência dita fundamental da ação legislativa no resultado final. Ele sustenta que essas são demonstrações de que o Legislativo aumentava paulatinamente o seu papel na formulação de po- líticas públicas e, ao mesmo tempo, incrementava o grau de controle que exercia sobre a implementação das mesmas. Segundo a análise, o Congresso conseguiu concessóes em troca do apoio concedido. Mesmo admitindo a correção de tais conclusões, me parece que Pojo novamente ignora que estas são questões surgidas a partir da segunda metade dos anos 1970, já durante o processo de liberalização política, no qual se previa o aumento lento e gradual da descompressão, inclusive no que se refere à atividade parlamentar. Da forma apresentada, tem-se a impressão de que o aumento de funções ocorreu devido à reconquista de poder pelo Legislativo, decorrente da opção pela conciliação, e que o Executivo, encurralado, teve que ceder.

Em resumo, com esses exemplos Pojo reafirma a sua tese referente aos benefícios de uma participação moderada e conciliadora por parte do Legislativo, do mesmo modo que o faz em relação às eleições municipais de 1976. Com relação a este pleito, até então, a tendência era de que, pela celeridade da apuração, fossem divulgados primeiro os resultados das capitais, onde a oposição geralmente vencia. Mas, após o triunfo político do Movimento Democrático Brasileiro (MDB) em 1974, os líderes do partido temiam que a manutenção dessa tradição pudesse acarretar uma tentativa de sabotagem por grupos de militares radicais. Como solução, montaram um sistema de apuração, através do Centro de Processamento de Dados do Senado (Prodasen), que privilegiou os resultados do interior, onde a Arena era mais forte. A estratégia funcionou, o que, para o autor, significa que o Parlamento cumpriu com competência o seu papel de informação de modo a colaborar com a liberalização.

O que também acho importante destacar é que, exceto na questão da Cocene, Antônio Carlos Pojo do Rego, assessor parlamentar, foi designado para trabalhar em todos os momentos citados. Não quero afirmar que por esta razão esses fatos são menos representativos. Sustento, porém, que um levantamento mais detalhado da ação legislativa no período mostraria com mais clareza se havia de fato a tendência de uma nova atuação por parte do Congresso ou se estas foram exceções dentro de um quadro de retração da atividade parlamentar. Assim como a vivência cotidiana da rotina do Congresso permitiu a Pojo o acesso a dados e in- 
formações e uma percepção mais clara do modus vivendi da instituição, talvez sua participação e filiação pessoal possam ter influenciado na seleção dos fatos e nas conclusões apresentadas, levando-o a supervalorizar o papel do Legislativo e os benefícios da atuação conciliadora.

Por último, cabe salientar o fato de o autor, em geral, não apresentar uma sequência temática ou cronológica muito clara ao longo do texto. $\mathrm{O}$ vaie-vem de temas e tempos prejudica a compreensão do leitor menos familiarizado com a questão. Creio que uma última revisão poderia ter resultado em um recorte mais preciso e na supressão das repetições que por vezes aparecem.

Apesar das ponderações, há que louvar o fato de $O$ Congresso Brasileiro e o Regime Militar refletir sobre uma característica muito particular e pouco considerada nas análises sobre a ditadura civil-militar brasileira: a gana pela construção de um regime estável em paralelo à busca por legitimação, com a opção pela participação institucional do Legislativo. Esta escolha resultou em constantes crises e rearranjos políticos ainda não suficientemente estudados.

\section{Notas}

${ }^{1}$ A tese foi defendida com o título: The Politics of Consultative Authoritarianism: The Brazilian Congress and the Military Regime (1964-1985).

${ }^{2}$ RODRIGUES, José Honório. Conciliação e reforma no Brasil: um desafio histórico-cultural. Rio de Janeiro: Civilização Brasileira, 1965.

3 ALVES, Márcio Moreira. O despertar da revolução brasileira. Lisboa: Seara Nova, 1974. 